\title{
Collection of Non-Human Source Plasma
}

National Cancer Institute

\section{Source}

National Cancer Institute. Collection of Non-Human Source Plasma. NCI Thesaurus.

Code C112935.

The collection of the fluid portion of non-human blood intended as a source material for further manufacture. 